\title{
Phytochemical profile and biological activities of 'Ora-pro-nobis' leaves (Pereskia aculeata Miller), an underexploited superfood from the Brazilian Atlantic Forest
}

\author{
Jéssica A.A. Garcia ${ }^{\mathrm{a}, \mathrm{b}}$, Rúbia C.G. Corrêa ${ }^{\mathrm{a}, \mathrm{b}, \mathrm{c}}$, Lillian Barros ${ }^{\mathrm{c}}$, Carla Pereira ${ }^{\mathrm{c}}$, Rui M.V. Abreu ${ }^{\mathrm{c}}$, \\ Maria José Alves ${ }^{\mathrm{c}}$, Ricardo C. Calhelha ${ }^{\mathrm{c}}$, Adelar Bracht ${ }^{\mathrm{a}, \mathrm{b}}$, Rosane M. Peralta ${ }^{\mathrm{a}, \mathrm{b}, *}$, \\ Isabel C.F.R. Ferreira ${ }^{\mathrm{c}, *}$ \\ ${ }^{a}$ Department of Biochemistry, State University of Maringá, Paraná, Brazil \\ ${ }^{\mathrm{b}}$ Graduate Program in Food Science, State University of Maringá, Paraná, Brazil \\ ${ }^{\mathrm{c}}$ Centro de Investigação de Montanha (CIMO), Instituto Politécnico de Bragança, Campus de Santa Apolónia, 5300-253 Bragança, Portugal
}

\section{A R T I C L E I N F O}

\section{Keywords:}

Pereskia aculeate

Hydroethanolic leaf extract

Phenolic composition

Antioxidant potential

Cell-based assays

Caftaric acid

\begin{abstract}
A B S T R A C T
Pereskia aculeata Miller, known worldwide as ora-pro-nobis, is a highly nutritive species of the Cactaceae family from the Brazilian Atlantic Forest. In this work, we report inedited information on the phenolic profile of $P$. aculeata leaves, besides a broad study of their antioxidant potential using a set of five different methods. A total of ten phenolic compounds were identified, such as two phenolic acids (caffeic acid derivatives) and eight flavonoids (quercetin, kaempferol and isorhamnetin glycoside derivatives). Caftaric acid was the extract's major phenolic constituent, accounting for more than $49 \%$ of the phenolic content, followed by quercetin-3-O-rutinoside (14.99\%) and isorhamnetin-O-pentoside-O-rutinoside (9.56\%). Overall, the ora-pro-nobis leaf extract showed relevant values of antioxidant capacity, with higher activities than the Trolox in the DPPH and ABTS trials. The antimicrobial activity exhibited by the extract against both Gram-positive and Gram-negative bacteria suggests the presence of a broad spectrum of phytochemicals with antibiotic activity.
\end{abstract}

\section{Introduction}

Pereskia aculeata Miller, popularly known as Barbados gooseberry and more commonly as ora-pro-nobis, is a type of Brazilian climbing cactus. It belongs to the Cactaceae family and Pereskioideae subfamily, is Native to South America and adapted only to low altitudes (Pinto, Duque, et al., 2015; Silva et al., 2017). Its succulent leaves are a great source of proteins $(26 \% \mathrm{w} / \mathrm{w})$, in this regard it is quite superior to other vegetables customarily used as foods, such as bean, corn or kale, and also presents important levels of minerals, dietary fiber, vitamins A and C, besides folic acid (Souza et al., 2016).

From South to Northeast of Brazil, ora-pro-nobis leaves are used in traditional cuisine, featuring as an ingredient of various sweet and savoury dishes. In some low-income communities, it is known as the 'meat of the poor', being the main protein source available (de Almeida, Simão, Corrêa, \& de Barros Fernandes, 2016; Pinto et al., 2016). So much that, in the city of Diamantina, Minas Gerais State, almost $80 \%$ of the population eats this nutritious protein-rich vegetable on a regular basis. $P$. aculeata leaves can be used in the preparation of salads, soups, omelettes and pies, and the leaf flour can serve as an enriching element in the formulation of breads, cakes, and pastas (Francelin et al., 2018). Furthermore, its mucilage can substitute eggs in food preparations (Almeida \& Corrêa, 2012), which is especially interesting for consumers with food allergies or diet restrictions. $P$. aculeata fruits can be applied in the manufacture of juices, jellies, mousses, and liquors; whereas its seeds can be germinated to produce edible shoots (Francelin et al., 2018).

In addition to its utilization as food, in folk medicine the leaves of ora-pro-nobis have been employed for centuries to treat renal disorders (with no signs of toxicity), to heal skin wounds and inflammatory processes, and as an effective emollient (Pinto \& Scio, 2014; Ademiluyi et al., 2016). Furthermore, there are reports of the utilization of some species of the genus Pereskia as a natural medicine against cancer (Pinto et al., 2012). In the past five years, several biological activities have been attributed to $P$. aculeata leaf extracts, including in vivo topical anti-inflammatory activity in models of acute and chronic dermatitis (Pinto, Machado, et al., 2015), wound healing activity (Pinto et al., 2016) and antinociceptive activity (Pinto, Duque, et al., 2015), in vitro

\footnotetext{
* Corresponding authors at: Department of Biochemistry, State University of Maringá, Paraná, Brazil (R.M. Peralta).

E-mail addresses: rosanemperalta@gmail.com (R.M. Peralta), iferreira@ipb.pt (I.C.F.R. Ferreira).
} 
antioxidant (Pinto et al., 2012; Sousa et al., 2014), and antimicrobial potentials (Souza et al., 2016), added to the antiproliferative activity against leukemia, neuroblastoma, and breast cancer cell lines (Pinto et al., 2012; Souza et al., 2016).

In spite of the aforementioned studies evidencing the nutritional and ethnopharmacological relevance of ora-pro-nobis leaves, information on their phytochemical constitution remains limited. The majority of the papers that performed chemical evaluation contemplated the amino acids and phytosterol profiles, also focusing on its essential oil (Pinto \& Scio, 2014; Pinto, Machado, et al., 2015; Souza et al., 2016; Zem, Helm, Henriques, Cabrini, \& Zuffellato-Ribas, 2017). A few works have indicated that phenolic compounds and carotenoids are the major antioxidant constituents of $P$. aculeata leaves (Agostini-Costa, Wondraceck, Rocha, \& Silva, 2012; Pinto et al., 2012; Pinto, Duque, et al., 2015), however, to our best knowledge, an advanced characterization of its phenolic constitution is lacking.

Natural bioactive extracts with antioxidant activities can be employed as substitutes for artificial additives, also preventing the development of ailments associated to oxidative stress, e.g. cancer, cardiovascular diseases and diabetes Mellitus. Likewise, the antimicrobial effects of some phytochemicals could delay or inhibit the growth of pathogenic and toxin-producing microorganisms in food, avoiding food-borne diseases and food spoilage (Corrêa et al., 2018). Hence, natural extracts and/or natural isolated compounds can cumulate the role of preservative and functionalizing ingredients, concurrently enhancing food products' stability and nutritional value (Gonçalves et al., 2019).

Considering the above, our aim was to perform an inedited study on the phytochemical profile and some biological activities of $P$. aculeata leaves, with the view of expanding the current knowledge on the potentialities of this superfood. For this purpose, its hydroethanolic extract was characterized in terms of phenolic composition, antioxidant, and antibacterial capabilities and finally the hepatotoxicity of the extract was evaluated.

\section{Materials and methods}

\subsection{Extract preparation}

Organic dried leaves of Pereskia aculeata (ora-pro-nobis), in the form of a flour, were bought from a reliable commercial brand (Ora Pro Nobis Brasil, Joinville, Santa Catarina, Brazil). The extract was prepared using a ratio flour/solvent of 1:20, with an extractor solution composed of $70 \%$ ethanol in deionized water. The vials were sealed and shaken for $2 \mathrm{~h}$ at $130 \mathrm{rpm}$, at room temperature and protected from light. This procedure was repeated for three cycles. Then, samples were centrifuged at $10^{\circ} \mathrm{C}$ and $10,000 \mathrm{rpm}$ during $15 \mathrm{~min}$, and the obtained supernatants were evaporated at $35{ }^{\circ} \mathrm{C}$ to remove the ethanol. Finally, the material was lyophilized (FreeZone 4.5 model 7750031, Labconco, Kansas City, MO, USA) and stored under freezing at $-20^{\circ} \mathrm{C}$.

\subsection{Determination of the phenolic compound profile}

Chromatographic analysis was carried out following the method established by the authors Bessada, Barreira, Barros, Ferreira, and Oliveira (2016), in a Dionex Ultimate 3000 UPLC system (Thermo Scientific, San Jose, CA, USA) equipped with a diode array detector (preferred wavelengths of 280,330, and $370 \mathrm{~nm}$ ) and an electrospray ionization mass detector (LC-DAD-ESI/MSn). Separation was completed with a Waters Spherisorb S3 ODS-2C18 $(3 \mu \mathrm{m}, 4.6 \mathrm{~mm} \times 150 \mathrm{~mm}$, Waters, Milford, MA, USA) column thermostatted at $35^{\circ} \mathrm{C}$. Mobile phases were $0.1 \%$ formic acid in water (A) and acetonitrile (B), within the following elution gradient: isocratic $15 \%$ B (5 min), $15 \%$ B to $20 \%$ B (5 min), $20-25 \%$ B (10 min), 25-35\% B (10 min), 35-50\% B (10 min), and re-equilibration of the column, with a $0.5 \mathrm{ml} / \mathrm{min}$ flow rate. MS detection was performed in negative mode, using a Linear Ion Trap LTQ
XL mass spectrometer (Thermo Finnigan, San Jose, CA, USA) equipped with an ESI source. Nitrogen served as the sheath gas (50 psi); the system was operated with a spray voltage of $5 \mathrm{kV}$, a source temperature of $325^{\circ} \mathrm{C}$, a capillary voltage of $-20 \mathrm{~V}$. The tube lens offset was kept at a voltage of $-66 \mathrm{~V}$. The full scan covered the mass range from $m / z$ 100-1500 and fragments were obtained until MS4. The collision energy used was 35 (arbitrary units). Data acquisition was carried out with the Xcalibur $^{\circledR}$ data system (Thermo Finnigan, San Jose, CA, USA). The identification of the phenolic components was accomplished by employing standard compounds (when available) and by comparison with available literature data. For each available phenolic standard (Extrasynthèse, Genay, France), calibration curves were built using the UV signal as a basis. Quantification was achieved utilizing the most fitting compound, with results expressed as mg per $\mathrm{g}$ of extract.

\subsection{Antioxidant activity evaluation}

To evaluate the antioxidant activity of the $P$. aculeata leaf extract, five methods were used: two cell-based methods (1) oxidative haemolysis inhibition assay (OxHLIA); (2) the inhibition of the production of thiobarbituric acid reactive substances (TBARS); besides three chemical in vitro assays (3) reduction of the 2,2-diphenyl-1-picrylhydrazyl radical (DPPH, Sigma-Aldrich, St. Louis, MO, USA); (4) reduction of the 2,2azino-bis (3-ethylbenzothiazoline-6-sulphonate) cation (ABTS, SigmaAldrich, St. Louis, MO, USA), and (5) hydroxyl radical scavenging assay. For all methods, successive dilutions of the stock solution were performed, and the positive control used was Trolox (6-hydroxy2,5,7,8-tetramethylchromane-2-carboxylic acid, Sigma-Aldrich, St. Louis, MO, USA); except for the hydroxyl radical assay, in which ascorbic acid was chosen for this role.

The DPPH and the ABTS tests were carried out following the methodology established by the authors (Corrêa et al., 2015). The hydroxyl radical sequestration capacity assay was conducted as described by $\mathrm{Mu}$ et al. (2012), whereas the TBARS assay was carried out according to Gonçalves et al. (2019). The results of these four tests were expressed as $\mathrm{IC}_{50}$ values (sample concentration supplying $50 \%$ of antioxidant activity).

The methodology employed in the OxHLIA assay is fully described in the recent work of Lockowandt et al. (2019). The erythrocytes used in this cell-based test were obtained according to the protocol of Evans et al. (2013). Summarily, in a 48-well microplate, $200 \mu$ of erythrocyte solution was mixed with $400 \mu \mathrm{l}$ of either PBS solution (control), antioxidant samples homogenized in PBS, or water (to induce full haemolysis). Subsequently with incubation $\left(37^{\circ} \mathrm{C}, 10 \mathrm{~min}\right.$, with shaking), $200 \mu \mathrm{l}$ of 2,2'-azobis(2-methylpropionamidine) dihydrochloride (160 mM in PBS) was incorporated and the plate was submitted to incubation under the same conditions. Then, optical density was assessed at $690 \mathrm{~nm}$ every $10 \mathrm{~min}$, with results expressed as delayed time of haemolysis $(\Delta t)$ (Takebayashi, Iwahashi, Ishimi, \& Tai, 2012). Finally, the obtained $\Delta \mathrm{t}$ values were correlated to the distinct sample concentrations, and from this correlation the inhibitory concentration (IC $\mathrm{I}_{50}$ value, $\mathrm{mg} / \mathrm{ml}$ ) capable to furnish a $20 \mathrm{~min}$ haemolysis delay $(\Delta \mathrm{t})$ was estimated.

\subsection{Hepatotoxicity evaluation}

The $P$. aculeata extract was dissolved in water (at $4 \mathrm{mg} / \mathrm{ml}$ ) and underwent extra dilutions. The sulforhodamine B assay was carried out to evaluate the extract's hepatotoxic potential in a porcine liver cell culture (PLP2), following a protocol established by the authors (Abreu et al., 2011) and using ellipticine (Sigma-Aldrich, St. Louis, MO, USA) as the positive control. Results were given in $\mathrm{GI}_{50}$ values, which is the concentration that constrained $50 \%$ of the net cell growth. 


\subsection{Antibacterial activity evaluation}

The minimal inhibitory and bactericidal concentrations (MIC and MBC) for all the bacterial strains were conducted using a previously described methodology by Pires et al. (2018). Five Gram-negative bacteria and three Gram-positive bacteria were used in this assay. The antibiotics ampicillin and imipenem were used as positive controls for the Gram-negatives, while ampicillin and vancomycin were used for the Gram-positives.

\subsection{Statistical analysis}

All obtained data were expressed as mean values and standard deviations (SD), as a result of three repetitions of the samples and concentrations that were employed in all analysis.

\section{Results and discussion}

\subsection{Phenolic compounds of P. aculeata leaf extract}

The phenolic compounds constitution and corresponding quantification of the hydroethanolic leaf extract of $P$. aculeate is presented in Table 1 and Fig. 1. A total of ten phenolic compounds were identified, among which two were phenolic acids (caffeic acid derivatives) and eight were flavonoids (quercetin, kaempferol and isorhamnetin glycoside derivatives). To our best knowledge, there are no reports in literature on the phenolic profile of Pereskia species.

Regarding phenolic acids, compounds 1 and $2\left([\mathrm{M}-\mathrm{H}]^{-}\right.$at $m / z$ 311) presented a fragmentation pattern that allowed assigning them as cis and trans isomers of caftaric acid, and compound $3\left([\mathrm{M}-\mathrm{H}]^{-}\right.$at $m / z$ 295) revealed a $\mathrm{MS}^{2}$ fragmentation and UV-Vis spectrum coherent to a caffeic acid, thus it was tentatively assigned as a caffeic acid derivative.

The chromatographic characteristics allowed the positive identification of quecetin-3-O-rutinoside (peak 6), kaempferol-3-O-rutinoside (peak 9), and isorhamnetin-3-O-rutinoside (peak 10), when comparing to the commercial standards. The remaining flavonoids were tentatively identified taking into account the chromatographic and MS characteristics, and literature information. Therefore, compounds $4\left([\mathrm{M}-\mathrm{H}]^{-}\right.$at $m / z 741)$ and $5\left([\mathrm{M}-\mathrm{H}]^{-}\right.$at $\left.m / z 595\right)$ were assigned as quercetin derivatives $\left(\lambda_{\max }\right.$ around $350 \mathrm{~nm}$; MS ${ }^{2}$ fragment at $m / z 301$ ), while compounds $7\left([\mathrm{M}-\mathrm{H}]^{-}\right.$at $\left.m / z 755\right)$ and $8\left([\mathrm{M}-\mathrm{H}]^{-}\right.$at $\left.m / z 609\right)$ were identified as isorhamnetin derivatives $\left(\lambda_{\max }\right.$ around $350 \mathrm{~nm}$; $\mathrm{MS}^{2}$ fragment at $m / z 315$ ). Compound 4 presented a $\mathrm{MS}^{2}$ fragmentation pattern revealing the alternative loss of a pentosyl $(\mathrm{m} / \mathrm{z}$ at 609 ; $-132 \mathrm{u})$ and deoxyhexosyl-hexoside $(\mathrm{m} / \mathrm{z}$ at $301 ;-308 \mathrm{u})$ residues, indicating location of each sugar moiety on different positions of the aglycone. The positive identification of different rutinosides, in the analyzed samples, suggested a rutinose identity for the deoxyhexosylhexose, therefore this compound was identified as quercetin-O-pentoside-O-rutinoside. Similarly, peak 5 indicated that it corresponds to a quercetin bearing a pentosyl and a hexosyl residues, and the observation of $\mathrm{MS}^{2}$ fragments at $\mathrm{m} / \mathrm{z} 477(-132 \mathrm{u})$ and $301(-162 \mathrm{u})$, also indicated the alternative loss of each residue, thus it was tentatively identified as quercetin- $O$-pentoside- $O$-hexoside. Comparable findings were taken into consideration to identify compounds 7 and 8 , which were identified as isorhamnetin- $O$-pentoside- $O$-rutinoside and isorhamnetin- $O$-pentoside- $O$-hexoside, respectively.

Caftaric acid was the major extracts' constituent accounting for more than $49 \%$ of the phenolic content $(11.72 \mathrm{mg} / \mathrm{g})$, followed by quercetin-3-O-rutinoside $(3.56 \mathrm{mg} / \mathrm{g})$ and isorhamnetin- $\mathrm{O}$-pentoside- $\mathrm{O}$ rutinoside $(2.27 \mathrm{mg} / \mathrm{g}$ ) (Table 1$)$. With some similarity, Hassanbaglou et al. (2012) found that catechin $(9.18 \mathrm{mg} / \mathrm{g})$; quercetin $(1.10 \mathrm{mg} / \mathrm{g})$; epicatechin $(1.09 \mathrm{mg} / \mathrm{g})$ and myricetin $(9.49 \mathrm{mg} / \mathrm{g})$ were the major flavonoid components of the ethanolic leaf extract of Pereskia bleo (Kunth). Pinto, Duque, et al. (2015) identified a different set of compounds when analysing the hydromethanolic fraction from a methanolic leaf extract of $P$. aculeate via UPLC-MS/MS in the positive ion mode, which included tryptamine, abrine, mescaline, hordenine, petunidin, di-tert-butylphenol isomers, and quercetin. Previously part of these compounds have been found in the active ethyl acetate fraction of a methanolic extract obtained from the leaves of Pereskia grandifolia (Haw) (Nurestri, Sim, \& Norhanom, 2009).

The total phenolic content found in our hydromethanolic extract were relevant $(23.75 \mathrm{mg} / \mathrm{g})$, with the amount of phenolic acids and flavonoids being almost equivalent. Total phenolic contents based on milligram of gallic acid equivalent (GAE) per gram of extract of different solvent extracts of $P$. aculeata leaves were estimated by Souza et al. (2016). The best phenolic content was found for the methanol extract $(15.04 \mathrm{mg} \mathrm{GAE} / \mathrm{g})$, followed by the ether extract $(11.78 \mathrm{mg}$ $\mathrm{GAE} / \mathrm{g}$ ) and chloroform extract (5.17 mg GAE/g). However, it is known that other types of compounds that may be present in abundance in plant extracts, such as reducing sugars and ascorbic acid, can also reduce the Folin Ciocalteu reagent, therefore resulting in overestimated values of total phenolic compounds by this method (Sánchez-Rangel, Benavides, Heredia, Cisneros-Zevallos, \& Jacobo-Velázquez, 2013).

\subsection{Evaluation of bioactive properties}

The antioxidant and antibacterial properties, as well as hepatotoxicity of the $P$. aculeata hydroethanolic extract were assessed and the results are shown in Tables 2 and 3.

Table 1

Retention time (Rt), wavelengths of maximum absorption in the visible region $\left(\lambda_{\max }\right)$, mass spectral data, tentative identification and quantification (mg/g) of the phenolic compounds present in the hydroethanolic extract from the leaves of Pereskia aculeata (mean \pm SD).

\begin{tabular}{|c|c|c|c|c|c|c|}
\hline Peak & Rt (min) & $\lambda \max (\mathrm{nm})$ & {$[\mathrm{M}-\mathrm{H}]^{-}(\mathrm{m} / \mathrm{z})$} & $\operatorname{MS}^{2}(m / z)$ & Tentative identification & Quantification (mg/g) \\
\hline 1 & 5.3 & 320 & 311 & $179(100), 149(82)$ & cis Caftaric acid(A) & $9.5 \pm 0.1$ \\
\hline 2 & 5.8 & 320 & 311 & $179(100), 149(82)$ & trans Caftaric $\operatorname{acid}^{(\mathrm{A})}$ & $2.22 \pm 0.07$ \\
\hline 3 & 8.6 & 320 & 295 & $179(100), 163(33), 133(47)$ & Caffeic acid derivative $\mathrm{e}^{(\mathrm{A})}$ & $0.57 \pm 0.01$ \\
\hline 4 & 15.8 & 353 & 741 & $609(100), 301(77)$ & Quercetin- $O$-pentoside- $O$-rutinoside ${ }^{(\mathrm{B})}$ & $2.11 \pm 0.02$ \\
\hline 5 & 17.1 & 352 & 595 & $463(68), 301(100)$ & Quercetin- $O$-pentoside- $O$-hexoside ${ }^{(\mathrm{B})}$ & $0.738 \pm 0.001$ \\
\hline 6 & 17.8 & 354 & 609 & $301(100)$ & Quercetin-3-O-rutinoside ${ }^{(\mathrm{B})}$ & $3.56 \pm 0.01$ \\
\hline 7 & 18.7 & 352 & 755 & 623(79), 315(100) & Isorhamnetin- $O$-pentoside- $O$-rutinoside ${ }^{(\mathrm{B})}$ & $2.27 \pm 0.02$ \\
\hline 8 & 20.5 & 350 & 609 & $477(45), 315(100)$ & Isorhamnetin- $O$-pentoside- $O$-hexoside ${ }^{(\mathrm{B})}$ & $0.63 \pm 0.01$ \\
\hline 9 & 21.2 & 342 & 593 & $285(100)$ & Kaempferol-3-O-rutinoside ${ }^{(\mathrm{B})}$ & $0.810 \pm 0.005$ \\
\hline \multirow[t]{4}{*}{10} & 22.2 & 352 & 623 & $315(100)$ & Isorhamnetin-3-O-rutinoside ${ }^{(\mathrm{B})}$ & $1.30 \pm 0.01$ \\
\hline & & & & & Total phenolic acids & $12.32 \pm 0.07$ \\
\hline & & & & & Total flavonoids & $11.4 \pm 0.1$ \\
\hline & & & & & Sum of phenolic compounds & $23.75 \pm 0.02$ \\
\hline
\end{tabular}

Standard calibration curves: A - caffeic acid ( $\mathrm{y}=388345 \mathrm{x}+406369 ; R^{2}=0.994 ; \quad$ LOD $=0.78 \mu \mathrm{g} / \mathrm{ml} ; \quad$ LOQ $\left.=1.97 \mu \mathrm{g} / \mathrm{ml}\right) ;$ B - quercetin 3 -O-glucoside $\left(\mathrm{y}=34843 \mathrm{x}-160173 ; R^{2}=0.9998 ; \mathrm{LOD}=0.21 \mu \mathrm{g} / \mathrm{ml} ; \mathrm{LOQ}=0.71 \mu \mathrm{g} / \mathrm{ml}\right)$. Linearity was performed with 11 levels $0.1-100 \mu \mathrm{g} / \mathrm{ml}$. 


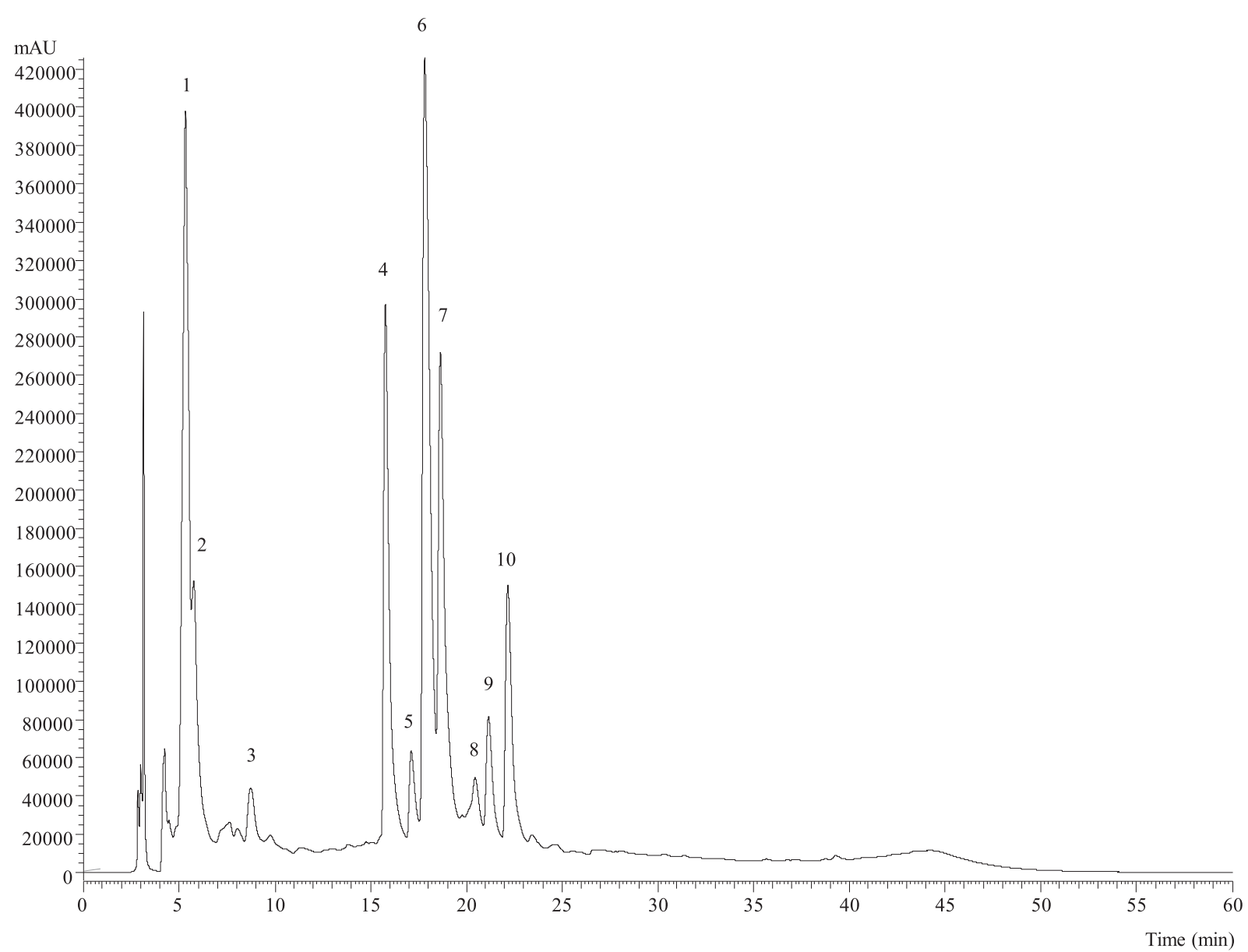

Fig. 1. Phenolic profile of $P$. aculeata leaf extract recorded at $370 \mathrm{~nm}$. Peak numbering is described in Table 1 .

\subsubsection{Antioxidant activity}

A set of different antioxidant methods were used to assess the antioxidant potential of the ora-pro-nobis leaf extract. It is essential to employ more than two assays to evaluate the antioxidant capacity of vegetal extracts, since antioxidant compounds act by distinct mechanisms, each having its particular target inside the reaction matrix (Gonçalves et al., 2019). Thereby, differing chemical reactivities implicate in distinct antioxidant activities in the chemical tests (Corrêa et al., 2017). The vast majority of the existing literature data on the antioxidant potential of Pereskia spp. were obtained exclusively using the DPPH scavenging assay. Thus, to our best knowledge, this is the first report on the investigation of $P$. aculeata extracts employing this ensemble of tests.

Overall, as shown in Table 2, our ora-pro-nobis leaf extract showed relevant values of antioxidant capacity, with higher activities than the Trolox in the DPPH and ABTS trials.

Sim, Sri Nurestri, \& Norhanom reported (2010), in their study on the bioactivities of Pereskia bleo (Kunth) DC., found a lower antioxidant potential $\left(\mathrm{IC}_{50}=210 \mu \mathrm{g} / \mathrm{ml}\right.$ ) determined by the DPPH assay. Likewise, Hassanbaglou et al. (2012) verified lower activities in ethyl acetate
$\left(\mathrm{IC}_{50}=168 \mu \mathrm{g} / \mathrm{ml}\right), \quad$ hexane $\quad\left(\mathrm{IC}_{50}=244 \mu \mathrm{g} / \mathrm{ml}\right), \quad$ methanol $\left(\mathrm{IC}_{50}=278 \mu \mathrm{g} / \mathrm{ml}\right)$, and ethanol $\left(\mathrm{IC}_{50}=540 \mu \mathrm{g} / \mathrm{ml}\right)$ extracts of $P$. bleo leaves using the same method. Pinto et al. (2012) investigated the antioxidant activity of the methanol crude extract, as well as of hexane, dichloromethane and ethyl acetate fractions of $P$. aculeata leaves via thin-layer chromatography DPPH bioautography analysis. The hexane fraction was the most active, due to its higher phenolic compound content. Souza et al. (2016) reported a much lower DPPH scavenging activity $\left(\mathrm{IC}_{50}=7.09 \mathrm{mg} / \mathrm{ml}\right)$ for a methanolic extract of $P$. aculeata, whereas Silva, Seifert, Schiedeck, Dode, and Nora (2018) found an antioxidant activity of $44.99 \mathrm{~g}$ of Trolox $/ \mathrm{kg}$ of fresh plant when also assessing a methanolic leaf extract of $P$. aculeata.

OxHLIA assay results are given as the concentration of each extract needed to prevent (delay) $50 \%$ of haemolysis for $30 \mathrm{~min}\left(\mathrm{IC}_{50}(30 \mathrm{~min})\right.$ and $60 \mathrm{~min}\left(\mathrm{IC}_{50}(60 \mathrm{~min})\right.$ ). Such haemolysis delay time standardization enables an easier comparative analysis of the extract antioxidant capability. Fig. 2 presents the time course of haemolysis at different and increasing extract concentrations. The $\mathrm{IC}_{50}(60 \mathrm{~min})$ value was more than 2 -fold the $\mathrm{IC}_{50}$ (30 min) value. For comparison purposes, Trolox used as a positive control. Trolox displayed a superior erythrocyte-protection

Table 2

Antioxidant activity of $P$. aculeata leaf extract and trolox (positive control) measured via inhibition assays, and the hepatotoxicity assessed in a porcine liver cell line (PLP2).

\begin{tabular}{|c|c|c|c|c|c|c|c|}
\hline & \multicolumn{2}{|l|}{ OxHLIA } & \multirow{2}{*}{$\begin{array}{l}\text { TBARS } \\
\text { IC }_{50}, \mu \mathrm{g} / \mathrm{ml}\end{array}$} & \multirow{2}{*}{$\begin{array}{l}\mathrm{DPPH} \\
\mathrm{IC}_{50}, \mu \mathrm{g} / \mathrm{ml}\end{array}$} & \multirow{2}{*}{$\begin{array}{l}\text { ABTS } \\
\mathrm{IC}_{50}, \mu \mathrm{g} / \mathrm{ml}\end{array}$} & \multirow{2}{*}{$\begin{array}{l}\mathrm{OH} \\
\mathrm{IC}_{50}, \mu \mathrm{g} / \mathrm{ml}\end{array}$} & \multirow{2}{*}{$\begin{array}{l}\text { Hepatotoxicity } \\
\mathrm{IC}_{50}, \mu \mathrm{g} / \mathrm{ml}\end{array}$} \\
\hline & $\mathrm{IC}_{50(30 \mathrm{~min})}, \mu \mathrm{g} / \mathrm{ml}$ & $\mathrm{IC}_{50 \text { (60 min })}, \mu \mathrm{g} / \mathrm{ml}$ & & & & & \\
\hline Pereskia aculeata & $57.0 \pm 3$ & $131.0 \pm 13$ & $39.0 \pm 3$ & $72.9 \pm 3$ & $40.5 \pm 1$ & $373.5 \pm 13$ & $>400$ \\
\hline Trolox & $5.5 \pm 0.5$ & $20.4 \pm 0.3$ & 9.2 & $113.9 \pm 11.0$ & $79.3 \pm 3.0$ & - & - \\
\hline
\end{tabular}


Table 3

Antibacterial potential of the Pereskia aculeata leaf extract.

\begin{tabular}{|c|c|c|c|c|c|c|c|c|}
\hline & \multicolumn{2}{|c|}{ P. aculeata } & \multicolumn{2}{|c|}{ Ampicillin $(20 \mathrm{mg} / \mathrm{ml})$} & \multicolumn{2}{|c|}{ Imipenem $(1 \mathrm{mg} / \mathrm{ml})$} & \multicolumn{2}{|c|}{ Vancomycin $(1 \mathrm{mg} / \mathrm{ml})$} \\
\hline & MIC & MBC & MIC & MBC & MIC & MBC & MIC & MBC \\
\hline \multicolumn{9}{|l|}{ Gram-negative bacteria } \\
\hline Escherichia coli & 20 & $>20$ & $<0.15$ & $<0.15$ & $<0.0078$ & $<0.0078$ & n.t. & n.t. \\
\hline Klebsiella pneumoniae & 5 & $>20$ & 10 & 20 & $<0.0078$ & $<0.0078$ & n.t. & n.t. \\
\hline Morganella morganii & 20 & $>20$ & 20 & $>20$ & $<0.0078$ & $<0.0078$ & n.t. & n.t. \\
\hline Proteus mirabilis & $>20$ & $>20$ & $<0.15$ & $<0.15$ & $<0.0078$ & $<0.0078$ & n.t. & n.t. \\
\hline Pseudomonas aeruginosa & 20 & $>20$ & $>20$ & $>20$ & 0.5 & 1 & n.t. & n.t. \\
\hline \multicolumn{9}{|l|}{ Gram-positive bacteria } \\
\hline Enterococcus faecalis & 10 & $>20$ & $<0.15$ & $<0.15$ & n.t & n.t & $<0.0078$ & $<0.0078$ \\
\hline Listeria monocytogenes & 5 & $>20$ & $<0.15$ & $<0.15$ & n.t & n.t & n.t & n.t \\
\hline MRSA & 5 & $>20$ & $<0.15$ & $<0.15$ & n.t & n.t & 0.25 & 0.25 \\
\hline
\end{tabular}

MIC - minimum inhibitory concentration; MBC - minimum bactericidal concentrations;

MRSA - Methicillin-resistant Staphylococcus aureus; n.t. - not tested.

capacity than the $P$. aculeata leaf extract, with an $\mathrm{IC}_{30}(60 \mathrm{~min})$ value of $5.5 \pm 0.5 \mu \mathrm{g} / \mathrm{ml}$. The extract was also evaluated by the TBARS method and the $\mathrm{IC}_{50}$ value obtained is in the same range as the OxHLIA IC $_{50}$ values. Curiously, Trolox was more than 10 -fold more potent than the tested extract in the OxHLIA method (5.5 compared to $57 \mu \mathrm{g} / \mathrm{ml}$ ), whereas 4-fold more efficient than the extract in the TBARS assay $(9.2$ compared to $39.02 \mu \mathrm{g} / \mathrm{ml}$ ).

According to their $\mathrm{IC}_{50}$ values, extracts can be categorized into four groups: highly active $\left(\mathrm{IC}_{50}<50 \mu \mathrm{g} / \mathrm{ml}\right)$; moderately active $\left(50<\mathrm{IC}_{50}<100 \mu \mathrm{g} / \mathrm{ml}\right)$; weakly active $\left(100<\mathrm{IC}_{50}<200 \mu \mathrm{g} / \mathrm{ml}\right)$ or simply inactive ( $\mathrm{IC}_{50}>200 \mu \mathrm{g} / \mathrm{ml}$ ) (Rai et al., 2017). In view of these parameters, in the TBARS assay the hydroethanolic extract displayed high antioxidant activity, whereas in the OxHLIA assay it presented a weak activity.

The bioactivities of our hydroethanolic leaf extract of $P$. aculeata are possibly related to its phenolic composition. Caftaric acid, the major phenolic constituent of the extract, is a non-flavonoid phenolic acid, found in various vegetable foods, more reportedly in grapes, which have been investigated for its antioxidant, anti-inflammatory and antimutagenic potentials. Zhang et al. (2011) attributed to this phytochemical the antimutagenic activity verified in the juice of Vitis coignetiae Pulliat against the carcinogenic heterocyclic amine 3-amino1-methyl-5H-pyrido [4,3-b]indole (Trp-P-2). Later, caftaric acid displayed inhibitory properties to biological macromolecule damages including protein, lipid, and DNA provoked by free radicals. Furthermore, it was capable of suppressing the decline of BV2 microglia cell viability and the production of NO and ROS induced by lipopolysaccharide (Liu et al., 2017).

Rutin, the second most important component of the $P$. aculeata extract, presents a wide range of pharmacological uses (as an antimicrobial, antifungal, and antiallergic agent) mainly due to its expressive antioxidant properties, especially as a free radical scavenger. Its strong antioxidant capacity against different antioxidant systems in vitro is concentration dependent (Gullón, Lú-Chau, Moreira, Lema, \& Eibes, 2017).

\subsubsection{Hepatotoxicity evaluation}

The assessed $P$. aculeata extract showed no toxicity against the liver primary culture PLP2, since the $\mathrm{GI}_{50}$ value was higher than the highest concentration tested $(400 \mu \mathrm{g} / \mathrm{ml}$ ) (Table 2). Silva et al. (2017) also studied the oral acute toxicity of an ethanolic extract of $P$. aculeata in rats. The authors performed a single dose gavage administration of plant extract, in the concentrations of $0 \mathrm{mg}, 1250 \mathrm{mg}, 2500 \mathrm{mg}$ and $5000 \mathrm{mg}$ of dry extract per $\mathrm{kg}$ of body weight. The acute toxicity investigation did not reveal any variation among the groups, neither in clinical evaluation nor in histopathological tests. In their review work over the bioactivities of the Pereskia genus, Pinto and Scio (2014) found no reports on the toxicity of Pereskia sp. for humans or animals. The absence of toxicity verified in our experiment, corroborates the in vivo results and endorses the use of $P$. aculeate leaves for food and therapeutic applications.

\subsubsection{Antibacterial activity}

The $P$. aculeata hydroethanolic extract minimum inhibitory concentration (MIC) values for five Gram-negative and three Gram-positive bacteria are presented in Table 3. The antimicrobial activity exhibited by the extract against both Gram-positive (Enterococcus faecalis, Listeria monocytogenes, MRSA - Methicillin-resistant Staphylococcus aureus) and Gram-negative (Escherichia coli, Klebsiella pneumoniae, Morganella morganii, Proteus mirabilis, and Pseudomonas aeruginosa) bacteria suggests the presence of a broad spectrum of phytochemicals with antibiotic activity. The extract was more active against $K$. pneumonia than the antibiotic ampicillin, whereas against $M$. morganii it presented equivalent inhibitory effect.

Overall, our hydroethanolic extract was more active against Grampositive bacteria than against Gram-negative bacteria. The same

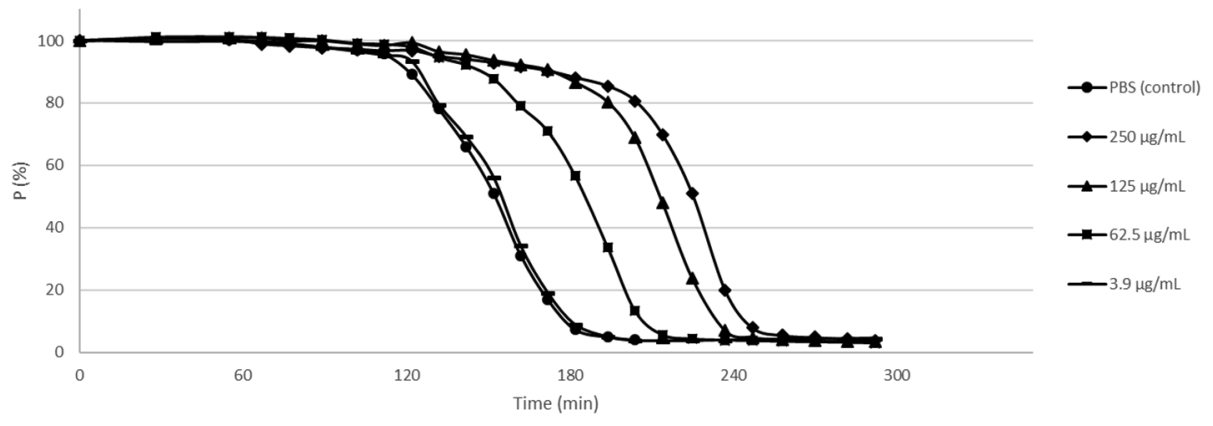

Fig. 2. Time course of haemolysis at different and increasing extract concentrations. 
tendency was observed by Souza et al. (2016) when evaluating the antibacterial activity of a chloroform leaf extract of Pereskia aculeata by means of the test of the inhibition halo on a plate agar, which observed a great efficiency of the extract against Staphylococcus aureus. On the other hand, the corresponding methanolic extract had strong antibacterial activity against Pseudomonas aeruginosa.

Philip et al. (2009) assessed the antibacterial activity of distinct fractions obtained from the methanol extract of Pereskia grandifolia leaves by agar diffusion method and found that the ethyl acetate fraction had a notable activity against Pseudomonas aeruginosa, Staphylococcus aureus, and Bacillus subtilis. Likewise, both the methanol and the ethyl acetate extracts of Pereskia bleo leaves were active against $P$. aeruginosa. Using the same method, Wahab et al. (2009) studied the antibacterial potential of $P$. bleo and found that its hexane and methanol extracts had higher activity against $P$. aeruginosa, whereas its dichloromethane extract was effective against methicillin-resistant $S$. aureus (MRSA).

The antibacterial activity of the Pereskia aculeata extract verified herein may relate, inter alia, to its rutin content. Soni, Malik, Singhai, and Sharma (2013) assessed the zone of inhibition of rutin in hydrogel systems against Staphylococcus aureus, Staphylococcus glurance and E. coli using a cup plate method and reported promising results. Furthermore, rutin has been applied to complement the antibacterial effect of other flavonoids (Gullón et al., 2017).

Our $P$. aculeata hydroethanolic extract presented MIC values higher than 1.6 for all tested bacteria, which some authors may classify as a weak inhibitor profile (Corrêa et al., 2018). Nonetheless, it should be considered that the bacteria herein used are clinical isolated multi-resistant strains, which in turn display antibiotic resistance profiles substantially superior to those of ATCC bacterial strains (Dias et al., 2016), reasoning why our results can be interpreted as indicatives of relevant antibacterial potential.

\section{Conclusion}

To our best knowledge, this is the first report on the detailed phenolic characterization of Pereskia aculeata leaves, as well as on the study of its antioxidant potential by the use of a set of different methods. Furthermore, we presented evidence of a promising antimicrobial potential, in addition to the verified absence of hepatotoxicity in PLP2 cells. The information reported here not only corroborates the importance of the production and consumption of $P$. aculeata leaves by the low income population to improve nutrition, but also reinforces their potential as a sustainable source of nutraceuticals and promising food ingredients to be used both for food enrichment and preservation.

\section{Declaration of Competing Interest}

The authors declare no conflict of interests.

\section{Acknowledgments}

J.A.A. Garcia thanks Coordenação de Aperfeiçoamento de Pessoal de Nivel Superior (CAPES) for the financial support provided for her masters studies in the State University of Maringá. R.C.G. Corrêa thanks Conselho Nacional de Desenvolvimento Científico e Tecnologia (CNPq) for financing her postdoctoral research at State University of Maringá (Process number 167378/2017-1). R.M. Peralta (Project number 307944/2015-8) and A. Bracht (Project number 304090/2016-6) are CNPq research grant recipients. The authors are grateful to the Foundation for Science and Technology (FCT, Portugal) and FEDER under Programme PT2020 for financial support to CIMO (UID/AGR/ 00690/2019), L. Barros, R. C. Calhelha and C. Pereirás contracts; to FEDER-Interreg España-Portugal programme for financial support through the project 0377_Iberphenol_6_E; the European Regional Development Fund (ERDF) through the Regional Operational Program
North 2020, within the scope of Project NORTE-01-0145-FEDER023289: DeCodE and project Mobilizador.

\section{References}

Abreu, R. M., Ferreira, I. C., Calhelha, R. C., Lima, R. T., Vasconcelos, M. H., Adega, F., Queiroz, M. J. R. (2011). Anti-hepatocellular carcinoma activity using human HepG2 cells and hepatotoxicity of 6-substituted methyl 3-aminothieno [3, 2-b] pyridine-2carboxylate derivatives: In vitro evaluation, cell cycle analysis and QSAR studies. European Journal of Medicinal Chemistry, 46, 5800-5806.

Ademiluyi, A. O., Oyeleye, S. I., \& Oboh, G. (2016). Biological activities, antioxidant properties and phytoconstituents of essential oil from sweet basil (Ocimum basilicum L.) leaves. Comparative Clinical Pathology, 25, 169-176.

Agostini-Costa, T. D. S., Wondraceck, D. C., Rocha, W. D. S., \& Silva, D. B. D. (2012). Carotenoids profile and total polyphenols in fruits of Pereskia aculeata Miller. Revista Brasileira de Fruticultura, 34, 234-238.

Almeida, M. E. F. D., \& Corrêa, A. D. (2012). Utilization of cacti of the genus Pereskia in the human diet in a municipality of Minas Gerais. Ciência Rural, 42, 751-756.

Bessada, S. M., Barreira, J. C., Barros, L., Ferreira, I. C., \& Oliveira, M. B. P. (2016). Phenolic profile and antioxidant activity of Coleostephus myconis (L.) Rchb. f.: An underexploited and highly disseminated species. Industrial Crops and Products, 89, 45-51.

Corrêa, R. C. G., de Souza, A. H. P., Calhelha, R. C., Barros, L., Glamoclija, J., Sokovic, M., Ferreira, I. C. (2015). Bioactive formulations prepared from fruiting bodies and submerged culture mycelia of the Brazilian edible mushroom Pleurotus ostreatoroseus Singer. Food \& Function, 6, 2155-2164.

Corrêa, R. C., Haminiuk, C. W., Barros, L., Dias, M. I., Calhelha, R. C., Kato, C. G., Ferreira, I. C. (2017). Stability and biological activity of Merlot (Vitis vinifera) grape pomace phytochemicals after simulated in vitro gastrointestinal digestion and colonic fermentation. Journal of Functional Foods, 36, 410-417.

Corrêa, R. C., Barros, L., Fernandes, Â., Sokovic, M., Bracht, A., Peralta, R. M., \& Ferreira, I. C. (2018). A natural food ingredient based on ergosterol: Optimization of the extraction from Agaricus blazei, evaluation of bioactive properties and incorporation in yogurts. Food \& Function, 9, 1465-1474.

de Almeida, M. E. F., Simão, A. A., Corrêa, A. D., \& de Barros Fernandes, R. V. (2016). Improvement of physiological parameters of rats subjected to hypercaloric diet, with the use of Pereskia grandifolia (Cactaceae) leaf flour. Obesity Research \& Clinical Practice, 10, 701-709.

Dias, M. I., Barros, L., Morales, P., Cámara, M., Alves, M. J., Oliveira, M. B. P., ... Ferreira, I. C. (2016). Wild Fragaria vesca L. fruits: A rich source of bioactive phytochemicals. Food \& Function, 7, 4523-4532.

Evans, B. C., Nelson, C. E., Shann, S. Y., Beavers, K. R., Kim, A. J., Li, H., ... Duvall, C. L. (2013). Ex vivo red blood cell hemolysis assay for the evaluation of pH-responsive endosomolytic agents for cytosolic delivery of biomacromolecular drugs. JoVE (Journal of Visualized Experiments), 73, e50166.

Francelin, M. F., Vieira, T. F., Garcia, J. A. A., Correa, R. C. G., Monteiro, A. R. G., Bracht, A., \& Peralta, R. M. (2018). Phytochemical, nutritional and pharmacological properties of unconventional native fruits and vegetables from Brazil. In S. A. Petropoulos, I. C. F. R. Ferreira, \& L. Barros (Eds.). Phytochemicals in vegetables: A valuable source of bioactive compounds (pp. 442-470). Sharjah, United Arab Emirates: Bentham Science Publishers.

Gonçalves, G. A., Corrêa, R. C., Barros, L., Dias, M. I., Calhelha, R. C., Correa, V. G., Ferreira, I. C. (2019). Effects of in vitro gastrointestinal digestion and colonic fermentation on a rosemary (Rosmarinus officinalis $\mathrm{L}$ ) extract rich in rosmarinic acid. Food Chemistry, 271, 393-400.

Gullón, B., Lú-Chau, T. A., Moreira, M. T., Lema, J. M., \& Eibes, G. (2017). Rutin: A review on extraction, identification and purification methods, biological activities and approaches to enhance its bioavailability. Trends in Food Science \& Technology, 67, 220-235.

Hassanbaglou, B., Hamid, A. A., Roheeyati, A. M., Saleh, N. M., Abdulamir, A., Khatib, A., \& Sabu, M. C. (2012). Antioxidant activity of different extracts from leaves of Pereskia bleo (Cactaceae). Journal of Medicinal Plants Research, 6, 2932-2937.

Liu, Q., Liu, F., Zhang, L., Niu, Y., Liu, Z., \& Liu, X. (2017). Comparison of chicoric acid, and its metabolites caffeic acid and caftaric acid: In vitro protection of biological macromolecules and inflammatory responses in BV2 microglial cells. Food Science and Human Wellness, 6, 155-166.

Lockowandt, L., Pinela, J., Roriz, C. L., Pereira, C., Abreu, R. M., Calhelha, R. C., Ferreira, I. C. (2019). Chemical features and bioactivities of cornflower (Centaurea cyanus L.) capitula: The blue flowers and the unexplored non-edible part. Industrial Crops and Products, 128, 496-503.

Nurestri, A. S., Sim, K. S., \& Norhanom, A. W. (2009). Phytochemical and cytotoxic investigations of Pereskia grandifolia Haw. (Cactaceae) leaves. Journal of Biological Sciences, 9, 488-493.

Mu, H., Zhang, A., Zhang, W., Cui, G., Wang, S., \& Duan, J. (2012). Antioxidative properties of crude polysaccharides from Inonotus obliquus. International Journal of Molecular Sciences, 13, 9194-9206.

Philip, K., Malek, S. N., Sani, W., Shin, S. K., Kumar, S., Lai, H. S., ... Rahman, S. N. (2009). Antimicrobial activity of some medicinal plants from Malaysia. American Journal of Applied Sciences, 6, 1613.

Pinto, N., Santos, R., Machado, D. C., Florêncio, J. R., Fagundes, E. M. Z., Antinarelli, L. M. R., \& Scio, E. (2012). Cytotoxic and antioxidant activity of Pereskia aculeata Miller. Pharmacology Online, 3, 63-69.

Pinto, N. D. C. C., \& Scio, E. (2014). The biological activities and chemical composition of Pereskia species (Cactaceae)-A review. Plant Foods for Human Nutrition, 69, 
189-195.

Pinto, N. D. C. C., Duque, A. P. D. N., Pacheco, N. R., Mendes, R. D. F., Motta, E. V. D. S., Bellozi, P. M. O., ... Scio, E. (2015). Pereskia aculeata: A plant food with antinociceptive activity. Pharmaceutical Biology, 53, 1780-1785.

Pinto, N. D. C. C., Machado, D. C., da Silva, J. M., Conegundes, J. L. M., Gualberto, A. C. M., Gameiro, J., ... Scio, E. (2015). Pereskia aculeata Miller leaves present in vivo topical anti-inflammatory activity in models of acute and chronic dermatitis. Journal of Ethnopharmacology, 173, 330-337.

Pinto, N. D. C. C., Cassini-Vieira, P., de Souza-Fagundes, E. M., Barcelos, L. S., Castañon, M. C. M. N., \& Scio, E. (2016). Pereskia aculeata Miller leaves accelerate excisional wound healing in mice. Journal of Ethnopharmacology, 194, 131-136.

Pires, T. C., Dias, M. I., Barros, L., Alves, M. J., Oliveira, M. B. P., Santos-Buelga, C., \& Ferreira, I. C. (2018). Antioxidant and antimicrobial properties of dried Portuguese apple variety (Malus domestica Borkh. cv Bravo de Esmolfe). Food Chemistry, 240, 701-706.

Rai, M., Paralikar, P., Jogee, P., Agarkar, G., Ingle, A. P., Derita, M., \& Zacchino, S. (2017). Synergistic antimicrobial potential of essential oils in combination with nanoparticles: Emerging trends and future perspectives. International Journal of Pharmaceutics, 519, 67-78.

Sánchez-Rangel, J. C., Benavides, J., Heredia, J. B., Cisneros-Zevallos, L., \& JacoboVelázquez, D. A. (2013). The Folin-Ciocalteu assay revisited: Improvement of its specificity for total phenolic content determination. Analytical Methods, 5, $5990-5999$.

Silva, D. O., Seifert, M., Nora, F. R., Bobrowski, V. L., Freitag, R. A., Kucera, H. R., Gaikwad, N. W. (2017). Acute toxicity and cytotoxicity of Pereskia aculeata, a highly nutritious Cactaceae plant. Journal of Medicinal Food, 20, 403-409.

Silva, D. O., Seifert, M., Schiedeck, G., Dode, J. S., \& Nora, L. (2018). Phenological and physicochemical properties of Pereskia aculeata during cultivation in south Brazil.
Horticultura Brasileira, 36, 325-329.

Sim, K. S., Sri Nurestri, A. M., \& Norhanom, A. W. (2010). Phenolic content and antioxidant activity of crude and fractionated extracts of Pereskia bleo (Kunth) DC. (Cactaceae). African Journal of Pharmacy and Pharmacology, 4, 193-201.

Soni, H., Malik, J., Singhai, A. K., \& Sharma, S. (2013). Antimicrobial and antiinflammatory activity of the hydrogels containing rutin delivery. Asian Journal of Chemistry, 25, 8371-8373.

Sousa, R. M., Lira, C. S., Rodrigues, A. O., Morais, S. A., Queiroz, C. R., Chang, R., ... de Oliveira, A. (2014). Antioxidant activity of Ora-Pro-Nobis (Pereskia aculeata Mill.) leaves extracts using spectrophotometric and voltammetric assays in vitro. Bioscience Journal, 30, 448-457.

Souza, L., Caputo, L., Inchausti De Barros, I., Fratianni, F., Nazzaro, F., \& De Feo, V. (2016). Pereskia aculeata Muller (cactaceae) leaves: Chemical composition and biological activities. International Journal of Molecular Sciences, 17, 1478.

Takebayashi, J., Iwahashi, N., Ishimi, Y., \& Tai, A. (2012). Development of a simple 96well plate method for evaluation of antioxidant activity based on the oxidative haemolysis inhibition assay (OxHLIA). Food Chemistry, 134, 606-610.

Wahab, S., Abdul, A., Mohan, S., Al-Zubain, A., Elhassan, M., \& Ibrahim, M. (2009). Biological activities of Pereskia bleo extracts. International Journal of Pharmacology, 5, 71-75.

Zem, L. M., Helm, C. V., Henriques, G. S., Cabrini, D. D. A., \& Zuffellato-Ribas, K. C. (2017). Pereskia aculeata: Biological analysis on wistar rats. Food Science and Technology, 37, 42-47.

Zhang, X., Ishida, R., Yuhara, Y., Kamiya, T., Hatano, T., Okamoto, G., \& ArimotoKobayashi, S. (2011). Anti-genotoxic activity of Vitis coignetiae Pulliat towards heterocyclic amines and isolation and identification of caftaric acid as an antimutagenic component from the juice. Mutation Research/Genetic Toxicology and Environmental Mutagenesis, 723, 182-189. 